\title{
Negociações (im)possíveis: a preceptoria e os desafios na relação entre ensino e serviço
}

(Im)possible negotiations: preceptorship and challenges in the teaching-service relationship

\author{
Flávia Queiroz Borges' (1) f.queiroz.borges@bol.com.br \\ Mariana Hasse 2 (1) mhasse@ufu.br \\ Janaína Paula Costa da Silva² (1) janaina.silva@ufu.br \\ Maria de Fátima Antero Sousa Machado ${ }^{3}$ (1) fatimaantero@uol.com.br \\ Flávia do Bonsucesso Teixeira ${ }^{2}$ (1) $\mid$ flavia.teixeira@ufu.br
}

\begin{abstract}
RESUMO
Introdução: O curso de Medicina da Universidade Federal do Triângulo Mineiro (UFTM) foi criado em 1954. Em 2011, ocorreu a inclusão dos estágios supervisionados em medicina geral e comunitária l e II no internato, que inseriu os estudantes na rede de serviços da atenção básica do município, processo marcado por conflitos e limitações. Visando solucionar os impasses criados, a UFTM contratou, por meio de concurso público, preceptores de medicina de família e comunidade para atuar na rede municipal.
\end{abstract}

Objetivo: Este estudo teve como objetivo analisar o arranjo institucional proposto para otimizar a relação ensino-serviço nos estágios supervisionados da área de medicina de família e comunidade, a partir da percepção de docentes e preceptores do Departamento de Saúde Coletiva que atuam na atenção primária.

Método: Trata-se de estudo de caso apoiado em pesquisa documental e entrevistas realizadas com três docentes e três preceptores do curso de Medicina de uma instituição pública.

Resultado: A análise temática revelou três núcleos que foram agrupados nas categorias "contexto difícil", "desencontro de expectativas" e "fios soltos". O "contexto difícil" exigia a negociação e o deslocamento de poder entre as instituições e seus agentes. A (con)fusão entre os papéis de docente e preceptor produziu"desencontro de expectativas". Em "fios soltos", a lacuna entre a universidade e a rede municipal parece intransponível e reiterada a partir do concurso.

Conclusão: A realização do concurso e a contratação de preceptores não foram suficientes para superar os desafios da articulação entre a universidade e a rede municipal de saúde. A pesquisa demonstra que não existe caminho simples para a integração ensino-serviço e que a interdependência dos atores aponta para o desafio e a necessidade da construção de agendas e espaços de decisão coletivos.

Palavras-chave: Preceptoria; Educação Médica; Serviços de Saúde; Atenção Primária à Saúde.

\begin{abstract}
Introduction: The Medical course at the Federal University of the Triângulo Mineiro (UFTM) was created in 1954. In 2011, the Supervised Internships in General and Community Medicine I and II were included in the clerkship program, which immersed students in the local Primary Care network - a process marked by conflicts and limitations. Aiming to solve the impasses created, UFTM hired, through a public tender, Family and Community Medicine preceptors to work in the municipal network.
\end{abstract}

Objective: To analyze the institutional arrangement proposed to optimize the teaching-service relationship in supervised clerkships in the area of Family and Community Medicine, from the perception of teachers and preceptors of the Department of Public Health who work in Primary Care.

Method: Case study supported by documentary research and interviews with three professors and three preceptors from the medical school of a public institution.

Result: Thematic content analysis revealed three core aspects that were grouped into the categories: "Difficult setting"; "Mismatch of expectations"; and "Loose threads". The "Difficult setting" demanded negotiation and a power shift between institutions and their agents. The (con)fusion between the roles of teacher and preceptor produced "Mismatches of expectations". In "Loose Threads," the gap between the university and the municipal network seems insurmountable and reiterated was after the public tender.

Conclusion: The public tender process and hiring of preceptors proved insufficient to overcome the challenges of connectivity between the university and the municipal health network. The research shows that there is no simple way to integrate teaching-service and that the interdependence of the actors points to the challenge and the need to build agendas and collective decision spaces.

Keywords: Preceptorship; Medical Education; Health Services; Primary Health Care.

1 Universidade Federal do Triângulo Mineiro, Uberaba, Minas Gerais, Brasil.

2 Universidade Federal de Uberlândia, Uberlândia, Minas Gerais, Brasil.

${ }^{3}$ Fundação Oswaldo Cruz, Rio de Janeiro, Rio de Janeiro, Brasil.

Editora-chefe: Rosiane Viana Zuza Diniz. ～～Editor associado: Jorge Carvalho Guedes.

Recebido em 13/05/21; Aceito em 03/10/21. | Avaliado pelo processo de double blind review. 


\section{INTRODUÇÃO}

A Faculdade de Medicina do Triângulo Mineiro (FMTM) foi fundada em 1953, e o curso de Medicina teve início em 1954. Tornou-se a primeira escola médica da região e a quarta no estado de Minas Gerais. O curso de Medicina manteve-se como a única graduação oferecida até o ano 1989, e a ampliação significativa de outros cursos da área da saúde ocorreu somente em 2005, após a alteração da classificação da instituição FMTM para Universidade Federal do Triângulo Mineiro (UFTM) ${ }^{1}$.

A primeira matriz curricular, de 1954, não mencionava carga horária por disciplina ou total do curso, mas demonstrava a orientação disciplinar e por especialidades. Nela os estágios estavam previstos apenas para o último ano da graduação². As modificações ocorridas entre 1954 e 2005 foram pontuais, limitadas à quantidade de disciplinas, natureza dos conhecimentos e carga horária prevista, sem reorganização do internato para o ensino na atenção básica ${ }^{3}$.

Nem a criação do Sistema Único de Saúde (SUS) parece não ter influenciado a orientação curricular do curso, tampouco o Programa Nacional de Incentivo a Mudanças Curriculares nos Cursos de Medicina ${ }^{4}$. Manteve-se uma matriz tradicional, com ausência de práticas para a formação de médicos generalistas e humanistas, um modelo distante do preconizado nas Diretrizes Curriculares Nacionais (DCN) para o curso de Medicina desde $2001^{3}$.

Somente em 2011 o Projeto Pedagógico do Curso (PPC) de Medicina foi modificado visando se adequar às DCN de 2001. Na matriz curricular vigente em 2013 e 2014, consta a existência do estágio supervisionado em medicina geral e comunitária I e II no décimo e $11^{\circ}$ períodos, respectivamente. Posteriormente, em 2017, o estágio supervisionado em medicina geral e comunitária I foi substituído pelo componente saúde coletiva que integra a disciplina Clínica Médica III, durante o nono período².

As DCN de $2014^{5}$ foram incorporadas na reformulação do currículo realizada em 2018. Parece uma tentativa de responder às demandas resultantes da promulgação da Lei $\mathrm{n}^{\circ}$ 12.871/2013, que instituiu o Programa Mais Médicos e prevê a formação de médicos para o SUS. Processo semelhante ocorreu em outras universidades do país ${ }^{6}$.

Essas atualizações entraram em vigor no segundo semestre de 2018, ainda com carga horária abaixo dos $30 \%$ de atuação na atenção básica e urgência e emergência preconizadas nas DCN ${ }^{5}$. Embora não tenham sido identificadas publicações que tratem do processo de negociação dos cenários de prática entre UFTM e a rede municipal de saúde de Uberaba, em Minas Gerais, o processo de inserção de estudantes na rede de serviços na atenção básica, particularmente na Estratégia Saúde da Família (ESF), tem se mostrado um desafio para as gestões da universidade e dos serviços de saúde ${ }^{6}$.
Um dos problemas é a demanda para que os médicos que trabalham nas equipes atuem como preceptores. Devido à sobrecarga das equipes em decorrência do excedente do número de famílias por território ${ }^{7,8}$, muitas vezes essa solicitação é interpretada como mais uma tarefa a ser gerenciada pelos profissionais do serviço.

Além disso, existe uma disputa por cenários de práticas entre instituições de ensino superior (IES) públicas e privadas que evidencia uma inequidade de condições, já que as IES privadas fornecem contrapartidas financeiras e/ou contratam preceptores especificamente para o acompanhamento dos estudantes, estratégias que, geralmente, não podem ser adotadas pelas IES públicas ${ }^{9}$.

Para fortalecer a integração entre ensino, serviços e comunidade no âmbito do SUS, foi instituída a Portaria Interministerial $\mathrm{n}^{\circ} 1.127$, de $2015^{10}$, com diretrizes para celebração do Contrato Organizativo de Ação Pública EnsinoSaúde (Coapes). Entretanto, até o momento do fechamento deste trabalho, Uberaba não possuía um Coapes assinado. Estava em vigor o Termo de Convênio SUS/Uberaba n 001/2016 ${ }^{11}$. Outros semelhantes foram firmados anteriormente, mas mostraram-se frágeis para garantir a presença dos estudantes do internato de medicina geral e comunitária nos cenários da ESF.

Nesse contexto de necessidade/desejo de mudanças, surgiu a proposta de criação de um cargo de médico de família e comunidade para atuar como preceptor para esse estágio. Discutido e aprovado pelo Departamento de Saúde Coletiva, resultou no lançamento dos editais para concurso público 22/2014, 16/2015, 20/2017 e 63/2017 $7^{12-15}$.

Nos três primeiros editais, constava como requisito título ou residência em medicina de família e comunidade. No último, a experiência de 12 meses em medicina de família e comunidade ou na atenção básica foi considerada suficiente ${ }^{12-15}$.

Após homologação dos resultados, cinco preceptores médicos tomaram posse, todos vinculados ao Departamento de Saúde Coletiva. Três também trabalham como médicos da ESF via prefeitura, e dois são contratados pela UFTM também para trabalhar no Centro de Atenção Integrada em Saúde (Cais).

Esses preceptores assumiriam o papel de docenteclínico, profissional que deve dominar a prática clínica e os aspectos educacionais relacionados a ela ${ }^{16}$, e ocupam uma posição de destaque na formação de estudantes da área da saúde para a atenção básica ${ }^{17,18}$.

A autora principal deste trabalho tomou posse como médica preceptora da UFTM no ano de 2015. Os desafios encontrados na integração ensino-serviço e os recorrentes questionamentos sobre a pertinência do cargo de preceptor em medicina de família e comunidade a motivaram a desenvolver sua pesquisa de mestrado. Seu estudo, que resultou neste artigo, 
teve como objetivo compreender a percepção de docentes e preceptores diretamente ligados às disciplinas Saúde Coletiva e Medicina Geral e Comunitária, sobre a contratação de preceptores em medicina de família e comunidade pela UFTM.

\section{MÉTODO}

Esta pesquisa é um estudo de caso apoiado em pesquisa documental e entrevistas realizadas com três docentes e três preceptores da UFTM. É incomum as universidades públicas contratarem - ainda mais por meio de concurso público profissionais especificamente para essa função. Foram identificados editais em outras IES apenas para contrato do médico preceptor por meio de processo seletivo.

Em geral, os docentes são responsáveis pela negociação dos cenários de prática e pela supervisão dos discentes, enquanto os médicos dos serviços ficam encarregados da preceptoria dos alunos. Por isso, a estratégia de contratação de preceptores de medicina de família e comunidade da UFTM foi identificada como elemento disparador para um estudo de caso, método que consiste na articulação de dados para descrever, explorar e compreender um contexto específico ${ }^{19}$.

Para a produção de dados, realizaram-se pesquisa documental e entrevistas. Os documentos consultados foram as atas de reuniões relacionadas à criação da vaga e elaboração dos editais, os editais dos concursos, o estatuto da UFTM, os projetos político-pedagógicos e as matrizes curriculares do curso de graduação em Medicina da UFTM, e os termos de convênio SUS/Uberaba.

Para as entrevistas, desenvolveram-se dois roteiros semiestruturados, um para preceptores e um para docentes. Ambos foram organizados em quatro núcleos, compostos por questões sobre as percepções e experiências com a preceptoria, a relação com o campo de prática, a preceptoria na formação médica e a relação ensino-serviço.

Entrevistaram-se três docentes e três preceptores técnicos administrativos envolvidos no estágio nas ESF dos estudantes no nono e $11^{\circ}$ períodos do curso de graduação em Medicina da UFTM. O universo total seria de oito servidores. Como a pesquisadora principal integra esse conjunto, o universo passou a contar com sete sujeitos que foram convidados a participar da pesquisa. Houve a recusa de um preceptor.

Todas as entrevistas foram realizadas de forma presencial, em salas da UFTM, pela pesquisadora principal. As entrevistas foram audiogravadas e transcritas integralmente.

Realizamos o processo de análise de dados por meio da análise de conteúdo ${ }^{20}$. Demandou três momentos de execução que não são excludentes: a pré-análise, a exploração do material e o tratamento dos dados quando realizamos a inferência e a interpretação ${ }^{20}$.
As etapas de análise realizadas de forma tão disciplinada foram fundamentais para promover um afastamento sistemático da pesquisadora principal que possibilitou refletir não sem algum sofrimento - sobre um processo no qual estava intimamente imbricada.

As categorias de análise identificadas se aproximam dos objetivos da pesquisa, mas pelo seu avesso, ou seja, pelo desconhecimento. Elas aludem às dificuldades da relação ensino-serviço e ao desencontro de expectativas entre os entrevistados, decorrente especialmente da confusão conceitual sobre o que é a preceptoria.

A pesquisa foi aprovada pelo Comitê de Ética em Pesquisas em Seres Humanos (CEP) da Universidade Federal de Uberlândia - UFU (Parecer n².717.118) em 2018.

\section{RESULTADOS}

A análise temática revelou três núcleos temáticos que foram agrupados nas categorias "contexto difícil", "desencontro de expectativas" e "fios soltos", apresentadas e discutidas a seguir.

\section{Contexto difícil}

Nessa categoria, abordamos as dificuldades da relação entre universidade e rede de saúde para a construção da interface ensino-serviço, representadas pela frágil relação com os preceptores da rede.

A principal barreira apontada pelos entrevistados para a implementação das atividades de ensino na atenção básica prevista no projeto político-pedagógico era a dificuldade de os médicos da ESF vinculados ao município de Uberaba aceitarem a função de preceptoria dos estudantes.

Ninguém obriga ninguém a fazer preceptoria. Eles podem receber os alunos, só que o envolvimento, a qualidade, eu não sei como vai ser. Um dos motivos da universidade ter feito esse concurso foi a dificuldade de ter preceptores, porque os meninos reclamavam que tinha lugares que eles iam e ficavam lá plantados olhando o médico atender, e o médico não trocava uma palavra com ele (Participante 06 - preceptor).

Segundo alguns entrevistados, a atuação voluntária como preceptores colocava os médicos da rede, docentes e estudantes envolvidos nessa interface ensino-serviço, em uma posição de desamparo: "A gente pedia por favor mesmo (Participante 01 - docente); “Tinha muito trabalho voluntário de preceptoria, que nos deixava constrangidos porque a universidade não assumia seu papel, e o município também não" (Participante 05 - docente).

Atuar como preceptor era compreendido como uma decisão individual, e, assim, ter um preceptor no campo de 
estágio dependia da disponibilidade e do desejo do médico da ESF. Assim, a proposta de incluir preceptores no quadro de servidores da UFTM veio como uma resposta às dificuldades de articulação entre universidade e rede de saúde.

Entretanto, o processo de criação do cargo de preceptor não se deu sem disputas. Embora caiba ao SUS ordenar a formação de profissionais da saúde e a Lei $n^{\circ} 8.080 / 90^{21}$ estabeleça que "os serviços públicos que integram o Sistema Único de Saúde (SUS) constituem campo de prática para ensino e pesquisa, mediante normas específicas, elaboradas conjuntamente com o sistema educacional", a forma como a preceptoria deve ser organizada não está clara. E isso se manifestou durante as discussões para criação do cargo. Alguns docentes entrevistados achavam que o trabalho do médico da ESF como preceptor deveria sem compulsório:

A gente tinha até profissionais do departamento com visões contrárias à contratação dos preceptores. Eles achavam que a gente deveria pressionar o município para que eles colocassem como uma exigência na contratação dos profissionais para a atenção primária que eles deveriam ser preceptores dos alunos. Bom, para começar, nós não temos poder de influenciar o município (Participante 05 - docente).

Outros, por entenderem que a organização do trabalho dos profissionais da ESF deve ser regida por metas - traduzidas em atendimentos/consultas realizadas -, afirmavam que eles não deveriam se ocupar com a preceptoria. Esse entendimento pressupõe uma gestão municipal, órgão responsável pela atenção básica, desvinculada do SUS, de seus princípios e diretrizes.

\section{Desencontro de expectativas}

A UFTM tinha expectativas de que a realização do concurso ajudasse na relação com a gestão municipal, especialmente no que se referia à preceptoria. Os profissionais médicos de família que prestaram e assumiram as vagas também tiveram suas motivações. $O$ desencontro entre essas expectativas é apresentado nessa categoria.

O problema da recusa dos profissionais em atuar como preceptores foi resolvido com o concurso. Entretanto, diferentes entendimentos sobre a função da preceptoria e o lugar do preceptor conservaram ruídos na relação ensino-serviço.

Todos os preceptores entrevistados referiram que, quando tomaram posse do cargo, não se sentiam preparados para exercer a função:

De início, achei que sabia, mas, depois que você parte pra prática, percebe que falta muita coisa. E na medida que você pesquisa sobre a educação médica ou tenta se capacitar, você percebe que não estava nada preparado na situação. Hoje eu acho que não estava preparado quando fiz o concurso (Participante 03 - preceptor).
Parece que deixar o lugar de voluntário e assumir um cargo "oficial" de preceptor desorganizou algo que pressupunham saber, uma vez que todos exerceram de forma voluntária a atividade de preceptoria antes do concurso.

Enquanto para os docentes o concurso era uma estratégia para garantir atenção aos estudantes durante a prática, ou seja, que os médicos recebessem os estudantes nos serviços, o fato de esses profissionais ingressarem na universidade como servidores acionou outras expectativas. Entre elas, a de ocupar um lugar no processo de aprendizagem, um lugar de educador que parecia obstaculizado enquanto eram preceptores voluntários: "Eu tinha vontade de ser professor... Eu preciso conhecer melhor essa função. Eu acho que preceptor é um facilitador" (Participante 02 - preceptor).

Entretanto, essa integração entre a universidade e os preceptores, ao menos até a realização deste trabalho, não ocorreu.

O que eu senti foi uma dificuldade de adaptação. A ligação que foi feita entre os preceptores e o departamento, eu achei que ficou faltando muita coisa. Faltou informação, diretrizes, foi um processo fragmentado da universidade em relação à gente. Faltou suporte, a gente caiu de paraquedas lá no departamento [de Saúde Coletiva, do qual fazem parte], e ninguém sabia do nosso trabalho, e a gente também não sabia do trabalho deles (Participante 06 - preceptor).

Os preceptores relatam que não participam de reuniões do departamento da UFTM do qual fazem parte porque ocorrem em horários em que eles estão com os estudantes, não havendo possibilidade concreta de encontro. Apesar de atuarem diretamente na educação dos futuros profissionais, os preceptores relatam que também não participam dos processos de formulação pedagógica do curso.

\begin{abstract}
O Projeto Pedagógico do Curso foi reformulado agora com as novas diretrizes curriculares. Eu estive em contato com o projeto propriamente dito quando eu participei de uma reunião no Coapes. [...] Então fuipara descobrir qual era o projeto pedagógico e não porque quando eu entrei alguém me trouxe. Eu não conhecia ao certo o que era (Participante 03 - preceptor).
\end{abstract}

Considerando que essas atividades constam nas tarefas administrativas e de gestão dos servidores, sua realização em horários incompatíveis com a presença dos preceptores desvela uma ausência de reconhecimento do status de pertencimento deles à universidade.

Entre os docentes e preceptores da disciplina Medicina Geral e Comunitária, há um contato maior, com horário noturno à parte reservado para discussões de estágio, programações e seminários nos quais todos participam. Essa estratégia, mesmo 
que fragmentada, parece contribuir para a constituição de uma percepção de pertencimento de grupo, mesmo que esporádica: "os preceptores eventualmente participam da vida do departamento" (Participante 01 - docente).

A leitura das atas das reuniões em que foram decididas as vagas dos preceptores evidencia que não havia uma descrição específica sobre o cargo. Destaca-se apenas a necessidade de responder a uma demanda específica da disciplina Medicina Geral e Comunitária. Essa dificuldade de entendimento sobre o papel do preceptor, mesmo entre preceptores, não é algo raro ${ }^{16}$.

Ainda no que se refere à integração com a universidade, os preceptores também tinham expectativas de que o vínculo com a academia qualificaria o trabalho deles como preceptores. Entretanto, outra lacuna com a UFTM se formou quando o Programa de Educação Permanente (PEP), que visava aprimorar o cuidado em saúde por meio da qualificação dos profissionais da atenção básica ${ }^{22}$, foi encerrado em 2016. Lançado em 2004, o programa era conduzido por universidades e cumpria muito bem a função de educação permanente dos preceptores e outros trabalhadores da atenção primária à saúde: "Eu fazia preceptoria de residência, e a gente tinha PEP e ajudava bastante. Agora não tem mais. Eu acho que era um espaço importante pra gente trocar ideias, aprimorar o trabalho" (Participante 2 - preceptor).

\section{Fios soltos}

Nessa categoria, são apresentados os resultados referentes ao descompasso, que se manteve mesmo com a realização do concurso, entre a UFTM e a gestão municipal dos serviços de saúde.

O concurso previa que os preceptores exercessem as funções na ESF, em que já havia médicos do município atuando. Como não houve pactuação prévia da UFTM com o município, não havia possibilidade de os dois profissionais exercerem suas funções de forma paralela. Assim, o arranjo possível foi que os preceptores concursados que já atuavam como médicos na ESF exercessem as duas funções ao mesmo tempo. Para garantir o cumprimento da carga horária destinada à preceptoria, as atividades de orientação e discussão de casos com os estudantes e as reuniões passaram a ser exercidas à noite.

Para dar conta desse problema, os preceptores que tinham vínculo apenas com a UFTM e não poderiam trabalhar na ESF do município, foram alocados no Cais, equipamento híbrido da UFTM com características de atenção básica e serviço especializado.

Lá tem uma perspectiva um pouquinho diferente. Porque lá tem médico, tem profissionais da residência multiprofissional e fica vinculado às seis equipes de saúde da família, que estão naquele entorno [...]. É um centro especializado, mas com características de família e comunidade. Em linhas gerais, aquele usuário passa pelas equipes de saúde da família, e o vínculo deles é com aquelas equipes. Só quando há uma demanda um pouco mais específica, aí eles são encaminhados para o Cais (Participante 01 -docente).

Mesmo com a presença de profissionais pertencentes ao quadro da UFTM, a relação entre a ESF e o Cais não se dá de forma fácil, repaginando uma dificuldade de diálogo comum entre atenção básica e especializada. Os preceptores da atenção básica ficam isolados dos preceptores especialistas da UFTM inseridos nas atenções secundária e terciária. Há pouca troca de informações, e a possibilidade para referenciar usuário é muito remota, o que aumenta as dificuldades para a atenção básica e o ensino.

Eusintoquefalta um contatomaiorcomauniversidade, uma possibilidade maior de referência ao paciente, trocar informações, receber um matriciamento, receber um suporte da atenção secundária. Isso poderia melhorar o processo de aprendizado dos estudantes, e o vínculo com a universidade ficaria melhor (Participante 06 - preceptor).

Mesmo estando intimamente ligadas, gestão municipal da saúde e universidade seguem distantes. A universidade continua não sendo percebida/se percebendo como SUS, embora gerencie serviços e profissionais de saúde. A gestão de saúde do município, especialmente após a garantia da presença de preceptores para os estudantes dada pelo concurso, segue displicente no diálogo com o ensino, devendo apenas ter ciência da existência dos discentes nas unidades de saúde e da programação de suas atividades.

A necessidade de aperfeiçoamento dessa relação entre profissionais e gestores do SUS e as IES demanda muitos arranjos e não é um desafio apenas no contexto estudado, sendo identificada também em outras pesquisas ${ }^{23,24}$.

\section{DISCUSSÃO}

Ao abordarmos aspectos da categoria "contexto difícil", deparamo-nos com os desafios de implementar currículos médicos que demandem novas práticas e inserção na rede de serviços. Trata-se de um processo que acontece em meio à desarticulação entre o previsto para a atenção básica e a realidade, além de envolver dificuldade de rompimento do isolamento da atenção básica, precária infraestrutura existente nas unidades de saúde e resistência de docentes e estudantes ${ }^{25,26}$.

É consensual que há um descompasso entre a exigência de profissionais formados para atenção básica e a persistência de processos formativos influenciados por especializações tecnológicas, pela indústria farmacêutica e pelo uso de equipamentos complexos ${ }^{9}$. 
A alta rotatividade e mesmo a ausência de médicos na ESF compõem o contexto difícil vivenciado em diversas localidades. Verifica-se insatisfação profissional provocada por sobrecarga de trabalho, baixo retorno financeiro, pouco reconhecimento profissional por parte de colegas e da população e falta de apoio político e de articulação entre escolas médicas e gestão municipal ${ }^{8}$.

Para nossos entrevistados, as dificuldades na inserção dos estudantes na ESF compõem esse contexto difícil, mas revelam situações comuns a outros locais.

Deparamo-nos com muitos conflitos decorrentes dos desafios de interseção entre esses dois mundos. Há queixas sobre a universidade estar no serviço sem levar em consideração os trabalhadores que estão lá, crítica que se amplia quando entra em cena a percepção de que os objetivos acadêmicos estão definidos a priori.

$\mathrm{O}$ contexto difícil retrata também o que Marin et al. ${ }^{24}$ relataram como "as contradições existentes no processo de gestão da integração ensino-serviço e a falta de clareza no contrato de parceria entre a academia e a secretaria da saúde". A instabilidade da função de preceptor exercida pelo médico da ESF sem vínculo com a universidade é evidenciada pelo uso do termo voluntário, o qual também revelou o desconhecimento/a descrença dos entrevistados na responsabilidade do SUS para "ordenar a formação de recursos na área da saúde"21. A atuação assistemática e a ausência de compromisso com horários desses preceptores revelam a não incorporação desse papel como dever do profissional do SUS a ser desempenhado no local de trabalho ${ }^{27}$.

Decorrente desse contexto difícil, a confusão entre os papéis de docente e preceptor parece produzir o enquadramento principal da categoria "desencontro de expectativas".

Na educação médica, a figura do preceptor, profissional que auxilia na formação dos graduandos e residentes, recebeu diferentes denominações, como docente clínico, supervisor, tutor e mentor, não ficando claras no Brasil as funções e atividades ligadas a cada um deles ${ }^{16}$. No entanto, a descrição apresentada por esses autores parece se aproximar da expectativa da instituição ao realizar o concurso para preceptor, especialmente no que se refere ao local de atuação.

As questões apresentadas nos resultados fizeram com que as práticas dos preceptores acabassem por se aproximar do que seria o papel do supervisor, o que acarretou uma identificação com os docentes e produziu uma insegurança quanto ao exercício da função. O componente pedagógico da preceptoria - base para a atuação do preceptor - parece ter adquirido significado para os entrevistados somente após o concurso.

Embora não haja um consenso sobre a definição de preceptor, pesquisadores apontam para a necessidade de que as atribuições sejam elucidadas e adequadas ao processo de aprendizagem proposto ${ }^{27}$. Entretanto, no caso estudado, o descompasso entre as expectativas de preceptores e universidade e a clara dificuldade de comunicação existente não geraram mobilização suficiente para que os preceptores fossem efetivamente integrados no cotidiano da universidade.

Apesar de pertencerem ao quadro de servidores da instituição de ensino, essa vinculação não garantiu a modificação na relação entre a instituição de ensino e os serviços de saúde. A distância entre aqueles que planejam e os que executam permaneceu produzindo os ruídos, abafados pela garantia de que os preceptores não se recusariam a receber os estudantes.

Em "fios soltos", a permanência da lacuna entre universidade e rede municipal é revelada e sinaliza que o "contexto difícil" não seria facilmente superado.

Ao analisarem a reforma curricular de um curso de Medicina do estado de São Paulo, pesquisadores apontaram que há uma interdependência de fatores para que a articulação entre comunidade acadêmica e administração da instituição e dos serviços públicos de saúde ocorra. Além da articulação política por parte daqueles que pretendem gerenciar o processo, é preciso que haja consonância entre esses diversos setores e a proposta ${ }^{28}$.

O Coapes, como instrumento de gestão, tem sido importante para mediar a integração ensino-serviço e poderia ser uma alternativa para encurtar a distância entre a UFTM e a rede municipal, e estruturar melhor a inserção dos preceptores nos serviços ${ }^{29}$. Mas em nenhum momento a ausência desse contrato no município foi problematizado pelos entrevistados.

Essa integração ensino-serviço é um dos eixos necessários para solidificar as novas propostas curriculares dos cursos de Medicina que visam promover condições satisfatórias para a qualificação profissional das atuais e futuras equipes de saúde ${ }^{30}$. Ela deveria ser compreendida como uma tarefa coletiva, construída entre docentes e trabalhadores que compõem as equipes dos serviços de saúde, visando, inclusive, garantir uma melhor assistência à população. Porém, no caso estudado, a contratação dos preceptores parece ter ocorrido no sentido unilateral de resolver um problema entendido como apenas da instituição de ensino, já que o próprio processo de definir as vagas e os espaços de atuação não foi partilhado com a gestão municipal.

As dificuldades nessa integração resultam das relações assimétricas de poder a que estão submetidos os diferentes atores institucionais, prevalecendo os interesses de grupos hegemônicos, o que muitas vezes contraria o posicionamento dos atores que estão diretamente envolvidos no processo ${ }^{31}$.

Ainda que as experiências anteriores de integração ensino-serviço comunidade tenham trazido poucos 
resultados na reorientação da formação médica, elas tiveram fundamental contribuição para gerar reflexões nas escolas que, progressivamente, deixaram de ver nesses processos apenas a oportunidade de campo de estágio e passaram a enxergálos como potenciais transformadores da realidade social e, consequentemente, do processo formativo ${ }^{32}$.

A parceria ensino-serviço promove melhora na qualidade do serviço porque a presença dos estudantes estimula os profissionais a desenvolver uma prática reflexiva, o que reorienta o serviço e amplia e qualifica suas práticas ${ }^{33-37}$. No entanto, a valorização da presença dos estudantes nesses cenários pelos profissionais e gestores das próprias unidades não é consenso ${ }^{38}$. O próprio processo que ocorreu na UFTM ilustra como ainda há dificuldade no entendimento do potencial que a inserção de estudantes e a atuação de preceptores nas ESF têm em aprimorar processos de trabalho na atenção à saúde.

A ausência de articulação informa o quanto são insuficientes esses arranjos que se operacionalizam apenas por meio de relações pessoais, geralmente estabelecidas sem a participação dos gestores nesses processos.

A contratação de preceptores para atuar na ESF é um indicativo de que a UFTM abdicou da tentativa de estabelecer parcerias mais qualificadas com a gestão municipal - e mesmo com outros equipamentos que integram o complexo de saúde da própria instituição - e descuidou-se da interação ensino-serviço.

Entretanto, a existência dos preceptores da UFTM materializa a interseção necessária entre gestão municipal e universidade. O fortalecimento de sua integração tanto com a rede como com a universidade, das quais os preceptores fazem parte, pode ser uma ponte e um convite para um projeto de superação dos ruídos nos processos de trabalho.

\section{CONCLUSÕES}

A realização do concurso e a contratação de preceptores não foram suficientes para superar os desafios da articulação entre a universidade e a rede de atenção à saúde. A pesquisa mostra que não existe caminho simples para superar as dificuldades da integração ensino-serviço e que a interdependência entre os atores requer a construção de agendas e espaços de decisão coletivos.

É necessário produzir consensos que aproximem o processo de trabalho dos serviços, organizado a partir de metas e produtividade, das demandas da instituição de ensino, e centrado em saberes teóricos e ferramentas metodológicas muitas vezes distantes da vida real.

A UFTM possui um compromisso histórico com a assistência e, ainda que não reconhecido diretamente pelos entrevistados, com a manutenção e construção do SUS. O processo de reorientação da formação médica é recente, e a mudança curricular pode potencializar a reflexão e o compartilhamento de saberes e práticas que promovam a distribuição de poderes entre as três esferas de gestão.

A ausência de ferramentas de gestão que estabeleçam a pactuação entre o município, responsável pela rede de serviços, e a universidade, responsável pela oferta dos cursos de graduação em saúde, enfraquece as possibilidades de integração. As diretrizes do SUS e das DCN, que estabelecem o serviço como espaço de formação, devem ser priorizadas pelos gestores de ambas as instituições para a construção conjunta de espaços dialógicos de formação de recursos humanos para o SUS, processo que oportunizara a melhoria dos processos de cuidado e de ensino.

\section{CONTRIBUIÇÃO DAS AUTORAS}

Inicialmente, o artigo foi concebido por Flávia Queiroz Borges, Flávia do Bonsucesso Teixeira e Mariana Hasse, respectivamente pesquisadora, orientadora e coorientadora da pesquisa que o originou. Realizaram a curadoria e análise dos dados. Em conjunto com as outras duas autoras, Janaína Paula Costa da Silva e Maria de Fátima Antero Sousa Machado, foram feitas a discussão dos resultados e revisão final do manuscrito.

\section{CONFLITO DE INTERESSES}

Declaramos não haver conflito de interesses.

\section{FINANCIAMENTO}

Declaramos não haver financiamento.

\section{REFERÊNCIAS}

1. Lopes SMG. A história da Faculdade de Medicina do Triângulo Mineiro: primeiros anos (1953-1960) [dissertação]. Uberlândia: Faculdade de Educação da Universidade Federal de Uberlândia; 2016 [acesso em 22 abr 2021].Disponívelem:https://repositorio.ufu.br/handle/123456789/18119.

2. Universidade Federal do Triângulo Mineiro. Projeto Pedagógico do Curso de Medicina. Uberaba: UFTM; 2017 [acesso em 28 abr 2021]. Disponível em: http://www.uftm.edu.br/medicina.

3. Sousa WDD. Identidade profissional docente no curso de Medicina da Universidade Federal do Triângulo Mineiro [dissertação]. Uberlândia: Universidade Federal de Uberlândia; 2011 [acesso em 20 abr 2021]. Disponível em: https://repositorio.ufu.br/handle/123456789/13867.

4. Brasil. Programa de Incentivo às Mudanças Curriculares para as Escolas Médicas (Promed). Brasília: Ministério da Saúde; 2002 [acesso em 2 out 2020]. Disponível em: https://pesquisa.bvsalud.org/portal/resource/pt/ lis-LISBR1.1-16915.

5. Brasil. Resolução CNE/CES no 3, de 20 de junho de 2014. Institui Diretrizes Curriculares Nacionais do Curso de Graduação em Medicina e dá outras providências. Diário Oficial da União; jun 2014 [acesso em 2 out 2020]. Disponível em: http://portal.mec.gov.br/index. php?option=com_docman\&view=download\&alias=14957-rces00114\&category_slug=janeiro-2014-pdf\&ltemid=30192.

6. Cândido PTS, Batista NA. O internato médico após as Diretrizes Curriculares Nacionais de 2014: um estudo em escolas médicas do estado do Rio de Janeiro. Rev Bras Educ Med. 2019;43(30):36-45. doi: 10.1590/1981-52712015v43n3rb20180149. 
7. Marqui ABTM, Jahn AC, Resta DG, Colomé ICS, Rosa N, Zanon T. Caracterização das equipes de saúde da família e seu processo de trabalho. Rev Esc Enferm USP. 2010;44(4):956-61. [acesso em 7 out 2020]. Disponível em: https://www.scielo.br/pdf/reeusp/v44n4/14.pdf.

8. Gonçalves RJ, Soares RA, Troll T, Cyrino EG. Ser médico no PSF, formação acadêmica, perspectivas e trabalho cotidiano. Rev Bras Educ Med. 2009;33(3):393-403. doi: 10.1590/\$0100-55022009000300009.

9. Vieira SP, Pierantoni CR, Magnago C, Ney MS, Miranda RG. A graduação em Medicina no Brasil ante os desafios da formação para a atenção primária à saúde. Saúde Debate. 2018;42(1):189-207. doi: 10.1590/010311042018 s113.

10. Brasil. Portaria Interministerial no 1.127 , de 4 de agosto de 2015 . Institui as diretrizes para a celebração dos Contratos Organizativos de Ação Pública Ensino-Saúde (COAPES), para o fortalecimento da integração entre ensino, serviços e comunidade no âmbito do Sistema Único de Saúde (SUS). Brasília; 2015 [acesso em 2 out 2020]. Disponível em: http://portalarquivos. saude.gov.br/images/pdf/2015/outubro/23/COAPES-PORTARIAINTERMINISTERIAL-N1.127\%20-DE-04\%20DE-AGOSTO-DE-2015.pdf.

11. Universidade Federal do Triângulo Mineiro. Termo de Convênio SUS/ Uberaba no 001/2016 [acesso em 7 out 2020]. Disponivel em: http:// www2.ebserh.gov.br/documents(147715/0/convencionais/a72eb4c6a93e-4dd4-82b1- 94af2b021af.

12. Universidade Federal do Triângulo Mineiro. Edital $n^{\circ} 22 / 2014$, de 27 de março de 2014 [acesso em 7 out 2020]. Disponível em: http://www.uftm. edu.br/concurso/admin/upoload/editais/Edital\%2022-14\%2029-4-14.pdf.

13. Universidade Federal do Triângulo Mineiro. Edital no 16/2015, de 25 de marços de 2015 [acesso em 7 out 2020]. Disponível em: http://www2.uftm. edu.br/concurso/admin/upload/editais/EDITAL\%20CP\%20MEDICO\%20F AMILIA\%2016-15.pdf.

14. Universidade Federal do Triângulo Mineiro. Edital n॰ 20/2017 [acesso em 7 out 2020]. Disponível em: http://appsite:uftm.edu.br/concursos/upload/ cronogramas/EDITAL\%2020- 17\%20e\%20Anexos\%20\%UBERABA.pdf.

15. Universidade Federal do Triângulo Mineiro. Edital no 63/2017 [acesso em 7 out 2020]. Disponível em: http://appsite.uftm.edu.br/concursos/upload/ cronogramas/EDITAL\%2063- 17\%20UBERABA\%20Anexos.pdf.

16. Botti IHO, Rego STA. Docente-clínico: complexo papel do preceptor na residência médica. Physis. 2011;21(1):65-85. doi: 10.1590/S010373312011000100005

17. Barreto VHL, Monteiro ROS, Magalhães GSG, Almeida RCC, Souza LN. Papel do preceptor da atenção primária em saúde na formação da graduação e pós-graduação da Universidade Federal de Pernambuco: um termo de referência. Rev Bras Educ Med. 2011;35(4):578-83. doi: 10.1590/S010055022011000400019

18. Missaka H, Ribeiro VWB. A preceptoria na formação médica: o que dizem os trabalhos nos congressos brasileiros de educação médica. Rev Bras Educ Med. 2011;35(3):303-10. doi: 10.1590/S0100-55022011000300002.

19. Bartlett L, Vavrus F. Estudos de caso comparado. Educ Real. 2017;2(3):899920. doi: 10.1590/2175-623668636.

20. Bardin L. Análise de conteúdo. Lisboa: Edições 70; 1977.

21. Brasil. Lei n 8.080, de 19 de setembro de 1990. Dispõe sobre as condições para a promoção, proteção e recuperação da saúde, a organização e o funcionamento dos serviços correspondentes e dá outras providências. Diário Oficial da União; 19 set 1990 [acesso em 28 abr 2021]. Disponível em: http://www.planalto.gov.br/ccivil_03/leis//8080.htm.

22. D'Ávila LS, Assis LN, Melo MB, Brant LC. Adesão no Programa de Educação Permanente para médico de família de um estado do Sudeste do Brasil. Cienc Saude Colet. 2014;19(2):401-16. doi: 10.1590/141381232014192.01162013.

23. Albuquerque VS, Gomes AP, Rezende CHA, Sampaio MX, Dias OV, Lugarinho RM. A integração ensino-serviço no contexto dos processos de mudança na formação superior dos profissionais da saúde. Rev Bras Educ Med. 2019;32(3):356-62. doi: 10.1590/S0100-550220080000300010.
24. Marin MJS, Oliveira MAC, Otani MAP, Cardoso CP, Moravcik MYAD, Conterno LO, et al. A integração ensino-serviço na formação de enfermeiros e médicos. Rev Bras Educ Med. 2013;37(4):501-8. doi: 10.1590/141381232014193.09862012.

25. Cecílio LCO, Reis AAC. Apontamento sobre os desafios ainda atuais da atenção básica à saúde. Cad Saude Publica. 2018;34(8):1-14 [acesso em 12 mar 2021]. Disponível em: https://www.scielo.br/pdf/csp/v34n8/16784464-csp-34-08-e00056917.pdf.

26. Alves CRL, Belisário SA, Lemos JMC, Abreu DMX, D'Ávila LS, Goulart LMHF. Mudanças curriculares: principais dificuldades na implementação do Promed. Rev Bras Educ Med. 2013;27(2):157-66 [acesso em 2 mar 2021]. Disponível em: https://www.scielo.br/pdf/rbem/v37n2/02.pdf.

27. Autonomo FROM, Hortale VA, Santos GB, Botti SHO. A preceptoria na formação médica e multiprofissional com ênfase na atenção primária análise das publicações brasileiras. Rev Bras Educ Med. 2015;39(2):316-27. doi: 10.1590/1981-52712015v39n2e02602014.

28. Pavan MV, Senger, MH, Marques W. Determinantes externos e internos da reforma curricular do curso de medicina da Pontifícia Universidade Católica de São Paulo. Rev Fac Cienc Med. Sorocaba. 2017;19(3):127-32. doi: 10.23925/1984-4840.2017v19i3a6.

29. Costa GAL. O procedimento do Contrato Organizativo de Ação Pública Ensino-Saúde (Coapes) nas 4a e $5^{a}$ regiões de saúde do Rio Grande do Norte [dissertação]. Caicó: Centro de Ciências da Saúde da Universidade Federal do Rio Grande do Norte; 2017 [acesso em 8 maio 2021]. Disponível em: https://repositorio.ufrn.br/jspui/handle/123456789/25033.

30. Baldoino AS, Veras RM. Análise das atividades de integração ensinoserviço desenvolvidas nos cursos de saúde da Universidade Federal da Bahia. Rev Esc Enferm USP. 2016;50(esp):17-24. doi: 10.1590/S0080623420160000300003.

31. Kuabara CTM, Sales PRS, Marin MJS, Tonhom SFR. Integração ensino e serviços de saúde: uma revisão integrativa da literatura. REME Rev Min Enferm. 2014;18(1):195-2017 [acesso em 2 maio 2021]. Disponível em: https://www.reme.org.br/artigo/detalhes/918.

32. Zarpelon LFB, Terencio ML, Batista NA. Integração ensino-serviço no contexto das escolas médicas brasileiras: revisão integrativa. Ciên Saúde Colet. 2018;23(12):4241-8. doi: 10.1590/1413-812320182312.32132016.

33. Santos MM, Nétto OBS, Pedrosa JIS, Vilarinho LS. PET-Saúde: uma experiência potencialmente transformadora no ensino de graduação. Interface (Botucatu). 2015;19(supl 1):893-901. doi: 10.1590/1807-57622014.1345.

34. Flores LM, Trindade AL, Loreto DR, Unfer B, Dall'Agnol MM. Avaliação do Programa de Educação pelo Trabalho para Saúde - PET- Saúde/Vigilância em Saúde pelos seus atores. Interface (Botucatu). 2015;19(supl 1):923-30. doi:10.1590/1807-57622014.1060.

35. Conceição MR, Vicentin MCG, Leal BMML, Amaral MM, Fischer $A B$, Kahhale EMP, et al. Interferências criativas na relação ensino-serviço: itinerários de um Programa de Educação pelo Trabalho para a Saúde (PETSaúde). Interface (Botucatu). 2015;19(supl 1):845-55. doi: 10.1590/180757622014.0894

36. Bezerra DF, Adami F, Reato LFN, Akerman M. A dor e a delícia do internato de atenção primária em saúde: desafios e tensões. ABCS Health Sci. 2015;40(3):164-70 [acesso em 20 abr 2021]. Disponível em: https:// pesquisa.bvsalud.org/portal/resource/pt/lil-771391.

37. Caldeira ES, Leite MTS, Rodrigues-Neto JF. Estudantes de Medicina nos serviços de atenção primária: percepção dos profissionais. Rev Bras Educ Med. 2011;35(4):477-85. doi: 10.1590/S0100-55022011000400006.

38. Mendes TMC, Bezerra HS, Carvalho YM, Silva LG, Souza CMCL, Andrade FB. Interação ensino-serviço-comunidade no Brasil e o que dizem os atores do cenário de prática: uma revisão integrativa. Ver Ciênc Plur. 2018;4(1):98116 [acesso em 22 abr 2021]. Disponível em: https://periodicos.ufrn.br/ rcp/article/view/14283. 